\title{
Identification and analysis of market risks in the activity of business associations
}

\author{
Oksana Pirogova ${ }^{*}$, Irina Zhilinkova ${ }^{1}$, and Vilena Zasenko ${ }^{1}$ \\ ${ }^{1}$ Peter the Great St. Petersburg Polytechnic University, Institute of Industrial Management, \\ Economics and Trade, Graduate School of Service and Trade, 195251, 29 Polytechnicheskaya str., \\ St. Petersburg, Russia
}

\begin{abstract}
The relevance of the study is because small business in the service sector is sensitive to external and internal shocks, more often than enterprises in other sectors of the economy are subject to bankruptcy. The activity of business associations, aimed at optimizing the business processes of their members, is an effective mechanism for supporting enterprises in the service sector, especially during an economic downturn. One of the important quantitative indicators of the effectiveness of business associations is the dynamics of the number of its membership base. The purpose of the study is to identify groups of risks and conduct a qualitative and quantitative analysis of the degree of their influence on the indicator that predetermines the prospects and nature of the survival of business associations. The result of the study is the creation of a risk map based on the Ishikawa model, in accordance with which it is determined that economic risks have the maximum impact on the volatility of the membership of a business association. Political, financial and managerial risks can also exacerbate destructive processes in the activities of business associations, especially during periods of economic depression. Industry risks do not significantly hinder the development of business associations. Thus, the conducted qualitative analysis of the reasons for the reduction in the number of the membership base of a business association makes it possible to find approaches to the creation of a system of indicators for assessing their market stability.
\end{abstract}

\section{Introduction}

Currently, service enterprises are undergoing a significant transformation. In addition to technological, social and innovative changes, changes and restructuring of the business model of small and medium enterprises are taking place. These transformations are primarily associated not so much with evolutionary changes, but are caused by the COVID19 pandemic, which had a huge impact on the traditional way of functioning of these enterprises and made significant changes in the ways and methods of their functioning [1].

According to the Federal Tax Service, at the end of 2019, there were 5.916 million small and medium-sized businesses in Russia, including 3.4 million individual

\footnotetext{
*Corresponding author: kafedra17@rambler.ru
} 
entrepreneurs [2]. The segment of small and medium-sized businesses employs about 15.3 million people throughout Russia. In the Russian Federation, since 2019, a national project "Small and Medium Business" has been launched. In accordance with it, by 2024, it is necessary to increase the number of people employed in small and medium-sized businesses to 25 million people, as well as to increase the contribution of this sector to GDP to $32 \%$, the share of exports of enterprises in this sector is planned to increase to $10 \%$ of the total volume of the country [3].

In the collection "Small and Medium Business in Russia" published by Rosstat [4] at the beginning of 2019, the structure of small and medium-sized businesses looked as follows (Fig. 1) [5].

The sectoral structure of small and medium-sized businesses in Russia in terms of turnover is shown in Fig. 1.

\section{By contribution to turnover}
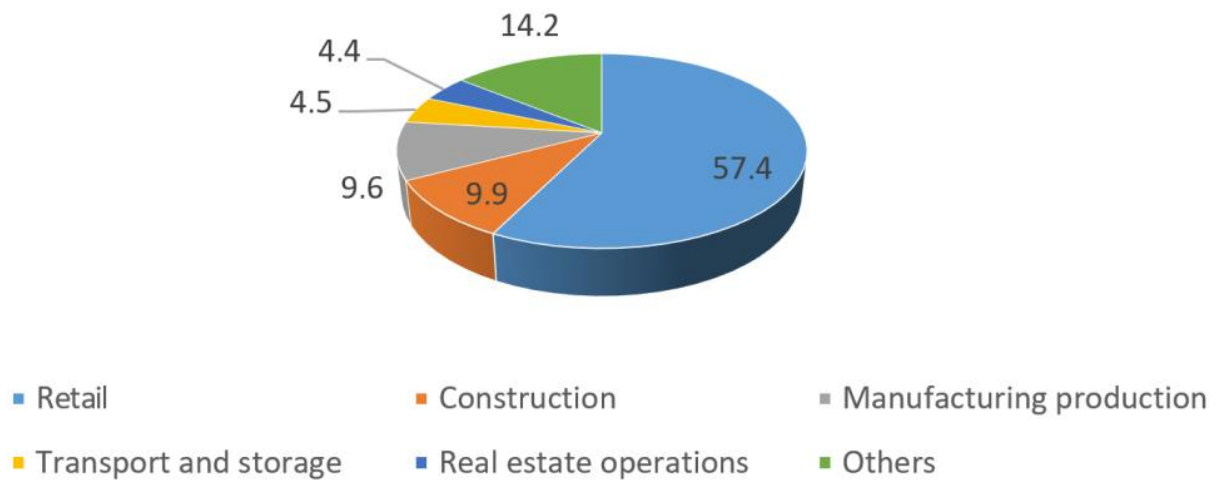

Fig. 1. Sectoral structure of small and medium-sized businesses by contribution to turnover.

The development of the pandemic had a significant impact on the dynamics of the functioning of small businesses, since sales fell rapidly starting from January and almost until the middle of the year, the personnel component in this sector also underwent a significant reduction, the possibility of lending for these entities practically ceased to exist, and the investment component was also reduced to minimum limits [6]. Thus, we can conclude that there is no incentive to create new micro-enterprises, the existence of existing SMEs is in a crisis zone, the availability of financial resources is absent, there are staff reductions in existing enterprises, and consumers who could support the business with their purchases are reducing them, so as well as experiencing problems with effective demand. Small business, in contrast to micro-enterprises, feels much better in this situation. Sales, having dropped significantly at the beginning of the year, were able to more or less recover by the middle of the year [7]. The availability of credit resources has been growing since the beginning of the year, which indicates the effectiveness of the support measures taken. At the same time, the staffing of enterprises is decreasing, which also demonstrates rather significant layoffs in the sector [8]. Investments have multidirectional dynamics from month to month, which suggests that companies have begun to develop, that have found niches to adapt to new conditions of existence: delivery, online sales, etc. In these conditions, it is necessary for small businesses to look for opportunities for further functioning in the current conditions. Therefore, the purpose of this study is to identify, analyze and assess the market risks of the activities of business associations in the service sector [9]. 


\section{Materials and methods}

From an economic point of view, business associations are one of the mildest forms of integration formations, the result of the integration of economic entities, i.e. management activities to unite or bring organizations closer together, aimed at ensuring joint activities and achieving a synergistic effect, carried out by various methods and in various forms, reflecting the peculiarities of the external and internal institutional environment of the participating organizations [10].

Integration formations of entrepreneurs are cooperation in various areas of legally and financially independent economic entities, in order to obtain economic advantages inherent in large business, contributing to the preservation of their market commercial stability as independent agents in the domestic and foreign markets (Figure 2).

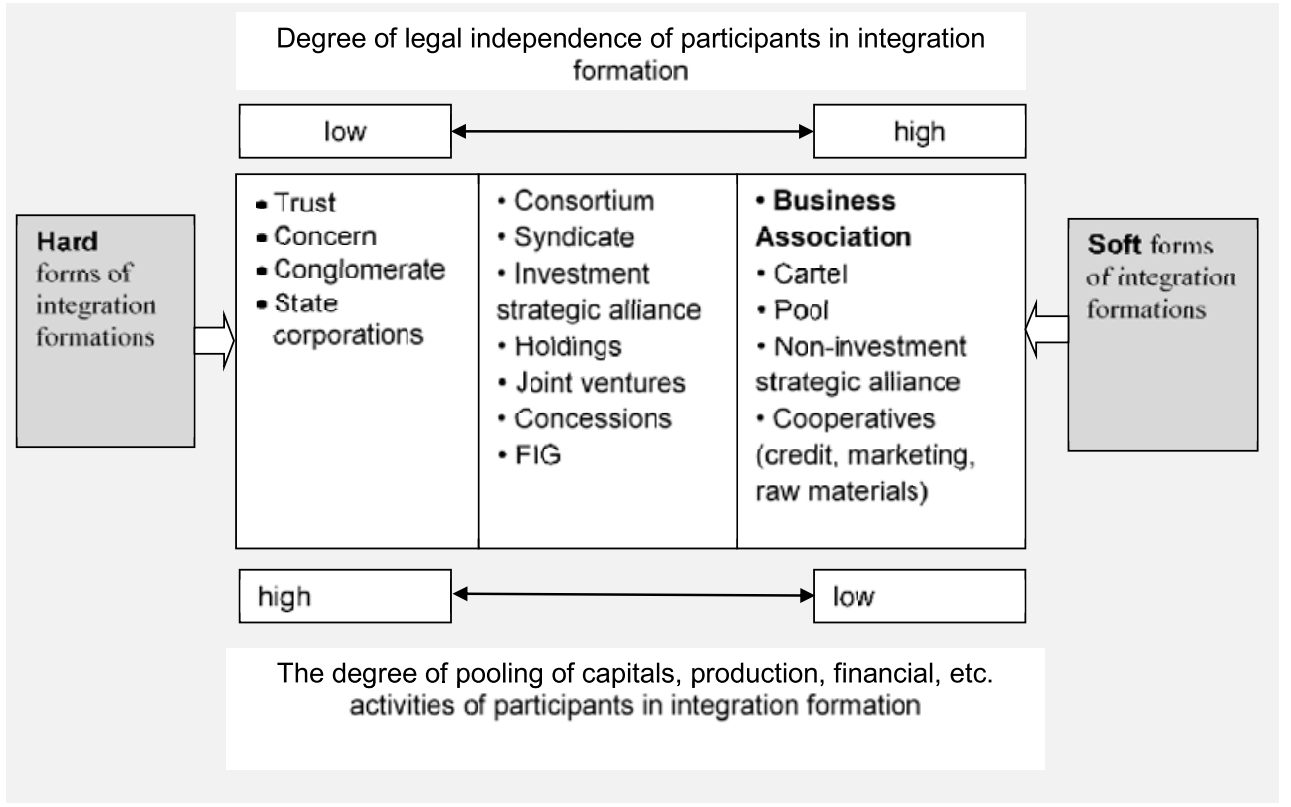

Fig. 2. Characteristics of the forms of integration formations.

"Business Association" as a form of integration education of business entities, including small businesses, is a non-profit, legally formalized association of entrepreneurial organizations, which is dominated by $[11,12]$ :

- horizontal or mixed integration relations;

- weak interaction between integrating economic entities based on voluntary cooperation;

- cooperation based on a long-term (strategic) basis;

- relations that generate competitive advantages for each of the members of formation, by reducing their internal, including transaction costs, optimizing technological and organizational-economic relations, improving the quality of human capital, etc.

A business association is a non-profit organization dedicated to meeting the needs of its members. Data on the scale of self-organization of entrepreneurs by analyzing the quantitative and qualitative dynamics of operating small and medium-sized business associations in Russia in the sectoral, functional and territorial context would provide an idea of the role and place of this institution in the Russian economy (Figure 3). 


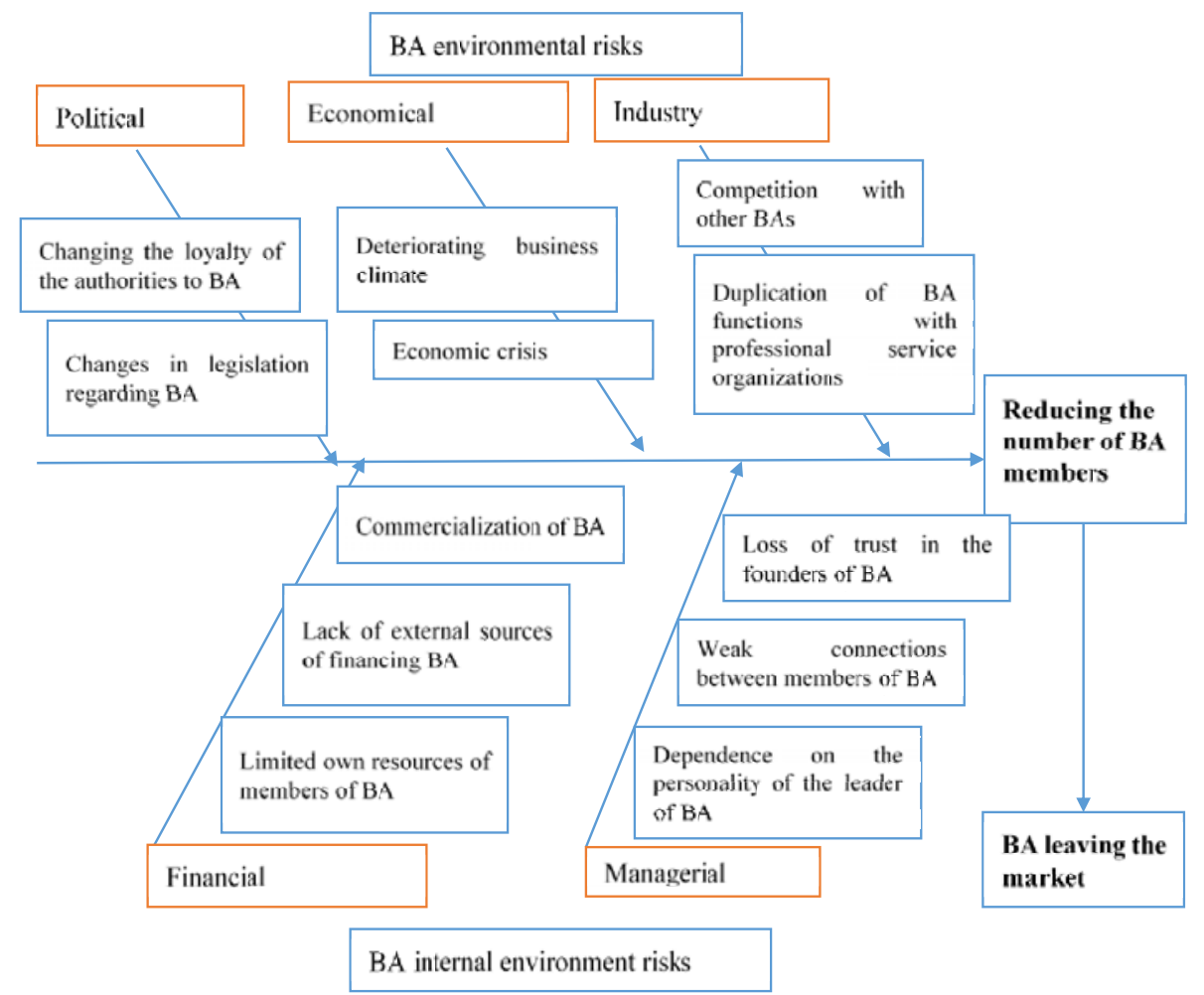

Fig. 3. Ishikawa's model of internal and external risks for the development of business associations.

Processing the resulting array of private indicators would serve as an information basis for assessing the size of their contribution to public welfare, which determines the degree of their effectiveness and sustainability [13].

The institutional effectiveness of business associations, especially small business in the service sector, can be viewed from the point of view of how much it is capable of realizing development opportunities and preventing threats to its existence. The Ishikawa diagram is applicable to determine the possible reasons for the reduction in membership in existing business associations (BA), which in turn leads, eventually, to the disappearance of a business association from the market space. Using this graphical method, you can eliminate the factors of the external and internal environment, which to a lesser extent affect the stability and survival of business associations.

\section{Results and discussion}

We will conduct a qualitative and quantitative analysis of the identified risk groups in order to assess the likelihood of their occurrence and the degree of impact on the socio-economic stability of the business association [14-16].

According to the degree of probability, risks are most often grouped into five categories (less often into three). For our study, a more detailed gradation is preferable (see table 1). Let us assign a certain point (rank) for each risk group. 
Table 1. The scale of the probability of occurrence of the identified risk group.

\begin{tabular}{|l|c|l|}
\hline $\begin{array}{c}\text { Probability of the } \\
\text { occurrence of a group of } \\
\text { risks }\end{array}$ & $\begin{array}{c}\text { Risk rank, } \\
\text { score }\end{array}$ & \multicolumn{1}{c|}{ Comment } \\
\hline Highly probable risks & 5 & $\begin{array}{l}\text { Expected events are usually inevitable and } \\
\text { regular for all BAs (they are cyclical) }\end{array}$ \\
\hline Possible risks & 4 & $\begin{array}{l}\text { Events may affect more than half of } \\
\text { existing BAs }\end{array}$ \\
\hline Medium probability risks & 3 & $\begin{array}{l}\text { Availability of evidence in favor of the } \\
\text { realization of the risk for half of BAs }\end{array}$ \\
\hline Unlikely risks & 2 & $\begin{array}{l}\text { Rare, isolated events for a small number of } \\
\text { BAs }\end{array}$ \\
\hline Low probability risks & 1 & $\begin{array}{l}\text { Events happen in exceptional cases for a } \\
\text { single BA }\end{array}$ \\
\hline
\end{tabular}

Thus, based on expert assessments, the rank of the probability of occurrence of each risk group is determined (Figure 4).

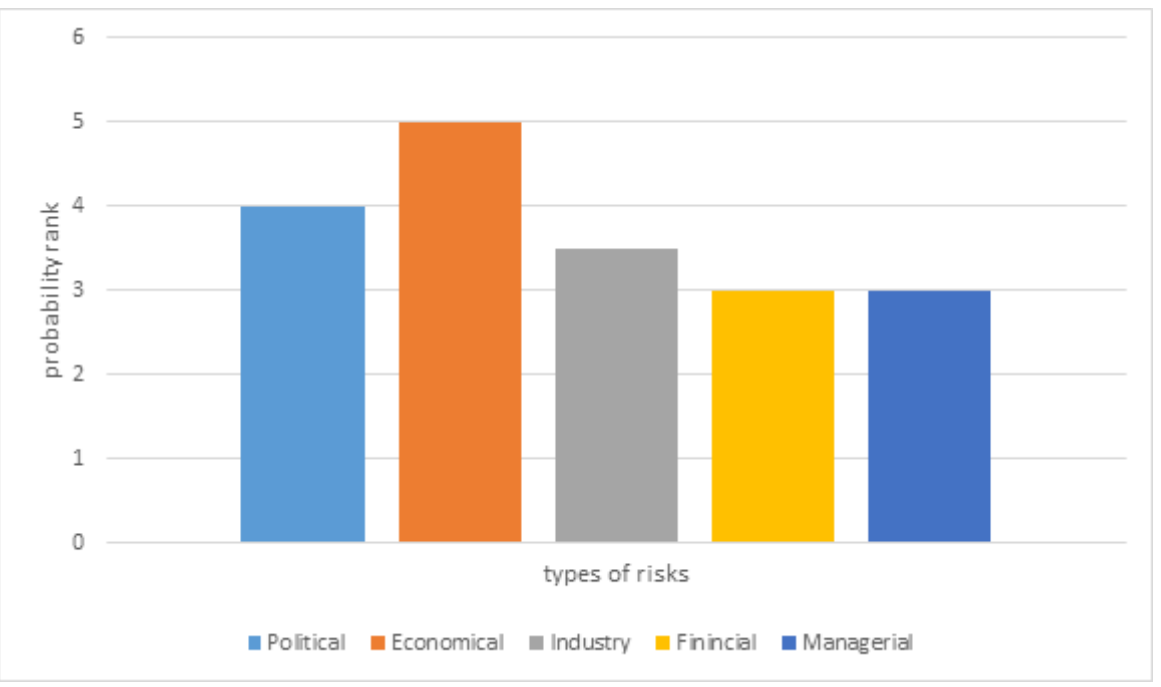

Fig. 4. Graphical display of the likelihood of risks of the external and internal environment for business associations.

Let's rank the risks according to the degree of their impact on the number of active members in the business association (see table 2).

Table 2. Scale of risks according to the degree of their impact on the number of active members of a business association.

\begin{tabular}{|c|c|c|}
\hline Impact degree & $\begin{array}{c}\text { Reduction in the number of members of BA } \\
\text { (in \% of the average listed value) }\end{array}$ & Risk grade \\
\hline Essential & From $50 \%$ to $70 \%$ & 5 \\
\hline Meaningful & From $30 \%$ to $50 \%$ & 4 \\
\hline Average & From $15 \%$ to $30 \%$ & 3 \\
\hline Small & From $5 \%$ to $15 \%$ & 2 \\
\hline Insignificant & From $0 \%$ to $5 \%$ & 1 \\
\hline
\end{tabular}


Now, based on expert assessments, we will determine the rank of the degree of impact of each group of external and internal risks (Figure 5).

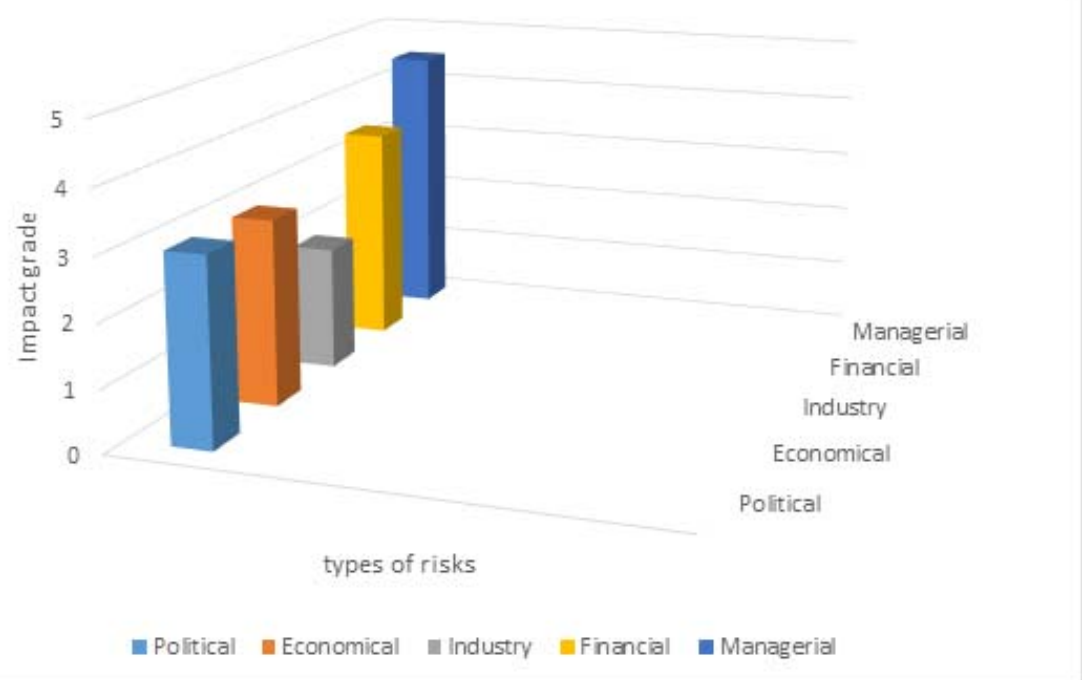

Fig. 5. Graphical display of the degree of impact of risks of the external and internal environment on membership in a business association.

We will group all types of risks in accordance with their rank of probability of occurrence and degree of impact (see table 3).

Table 3. Grouping of risks according to the rank of probability and impact.

\begin{tabular}{|c|l|c|c|}
\hline № & Risk factor name & Probability rank & Impact grade \\
\hline 1 & Political risks & 4 & 3 \\
\hline 2 & Economical risks & 5 & 3 \\
\hline 3 & Industry risks & 3.5 & 2 \\
\hline 4 & Financial risks & 3 & 3.5 \\
\hline 5 & Managerial risks & 3 & 4.5 \\
\hline
\end{tabular}

After assigning each risk a rank according to both criteria, we will build a risk map, which can be used to illustrate which risks pose a major threat to the reduction of members of the business association, and which risks the business association should tolerate (see Figure 6).

Industry risks have a relatively low impact on the dynamics of the membership base of business associations. They are located on the border of the green and yellow zones and are assessed as acceptable risks ( 7 points), i.e. not requiring the use of special measures to neutralize them. Indeed, the presence on the market of organizations with similar market services, with a competent management policy, contributes to the strengthening and gives additional dynamism to the development of a business association.

The analysis of the risk map shows, in general, a moderate impact of political, financial and managerial risks on the stability of the membership base of business associations focused on the needs of small businesses in the service sector. They are in the yellow zone with a value of 12.10 .5 and 13.5 points, respectively. When assessing the effectiveness of a specific business association and the prospects for its survival, in our opinion, special attention should be paid to the nature of management risks. The initiative to create many regional industry business associations comes from a charismatic, authoritative personality of a specific entrepreneur who is able to gather like-minded people around him. However, 
when a leader leaves the business association, the activities of the business structure created by him often cease. Therefore, building a system of organizational relationships between members of a business association, in such a way that business processes and business relationships are not confined to a separate manager, neutralizes the risks of the collapse of the business association for this reason.

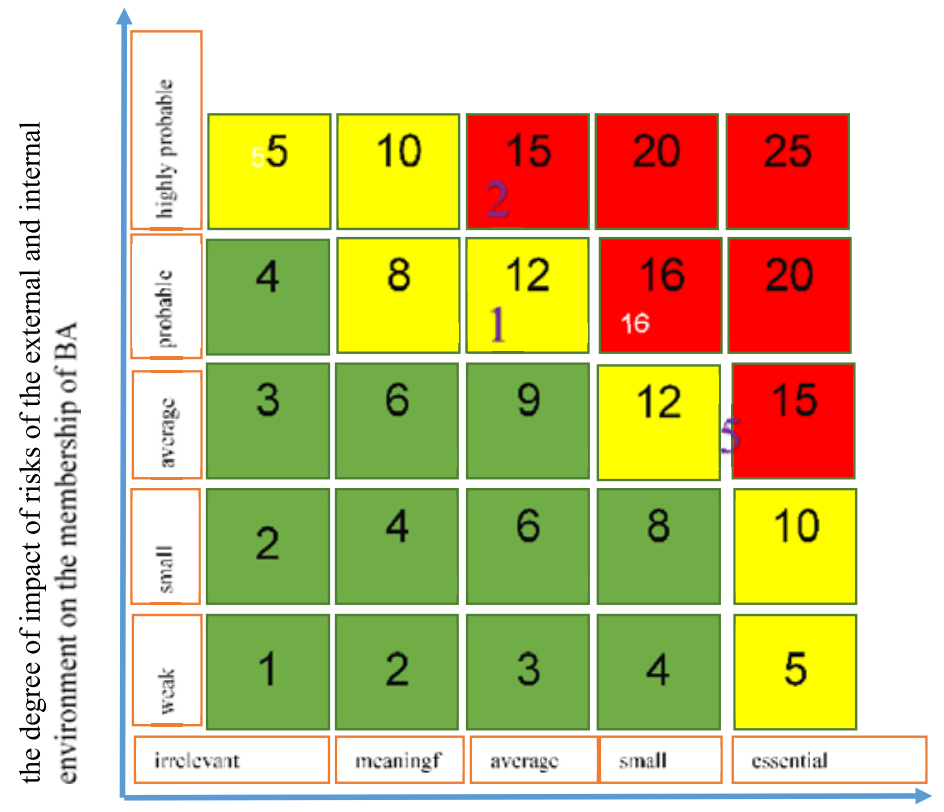

Degree of reduction in the number of BA members, points

Fig. 6. Map of risks of volatility in the number of members of a business association.

Largely, business associations are sensitive to economic risks, which lead to sharp fluctuations in the number of members of business associations during periods of unfavorable market conditions. It is small business in the service sector that is sensitive to all external and internal shocks that lead them to bankruptcy more often than enterprises in other sectors of the economy, which was once again confirmed during the pandemic period. According to a study by IHS Markit, the PMI index of the service sector in the Russian Federation in March fell from 52 in the middle of the first quarter of 2020 to 37.1 points [16]. Withdrawal from the market of enterprises naturally means termination of membership in the relevant industry business association. Consequently, the development of a system of events by business associations and the improvement of the system of business services aimed at minimizing costs and activating the hidden economic potential of their members will contribute to the stability and dynamism of the development of the business association itself.

\section{Conclusion}

Based on Ishikawa's model, the process of termination of the activity of a business association due to the reduction in the number of its members was tested. We identified and carried out a quantitative and qualitative analysis of the group of risks of the external environment (political, economic and sectoral) and the internal environment (financial and management). The result of the study is the creation of a risk map, in accordance with 
which it is determined that the maximum impact on the volatility of the membership of a business association is provided by economic risks. Political, financial and managerial risks can also exacerbate destructive processes in the activities of business associations, especially during periods of economic downturn. Industry risks are acceptable (7 points) and do not significantly hinder the existence and development of business associations. Thus, the qualitative analysis of the reasons that ultimately lead to the termination of the activities of business associations allows us to find approaches to creating a system of indicators for assessing their effectiveness.

\section{References}

1. A. Ajupov, A. Sherstobitova, S. Syrotiuk, A. Karataev, International Science Conference SPbWOSCE-2018 "Business Technologies for Sustainable Urban Development” 110, 02040 (2019) DOI 10.1051/e3sconf/201911002040

2. A. Sergeev, L. Akhmetshina, K. Grabovyy, International Science Conference SPbWOSCE-2018 “Business Technologies for Sustainable Urban Development” 110, 02153 (2019) DOI 10.1051/e3sconf/201911002153

3. A. Mecke, I. Lee, J.R. Baker jr., M.M. Banaszak Holl, B.G. Orr, Eur. Phys. J. E 14, 7 (2004)

4. O. Kravchenko, M. Leshchenko, D. Marushchak, Y. Vdovychenko, S. Boguslavska, The 8th International Conference on Monitoring, Modeling \& Management of Emergent Economy 65, 07004, (2019) DOI 10.1051/shsconf/20196507004

5. E. Voskresenskaya, L.Vorona-Slivinskaya, L. Achba, Environmental and Resource Economics 164, 09016 (2020) DOI 10.1051/e3sconf/202016409016

6. O. Pirogova, E. Gorin, V. Plotnikov, E3S Web of Conferences 91, 08021 (2019)

7. V. Plotnikov, O. Pirogova, Key Competencies as an Enterprise Value Management Tool, IBIMA 2018, 1716-1721 (2018)

8. J. Yoshida, Pacific-Basin Finance Journal 61, 101290 (2020) https://doi.org/10.1016/j.pacfin.2020.101290

9. M. Martín-Peña, J. Sánchez-López, E. Díaz-Garrido, Journal of Business \& Industrial Marketing 35(3), 564-574 (2018) https://doi.org/10.1108/JBIM-12-2018-0400

10. E. Fang, W.R. Palmatier, J.-B.E. Steenkamp, Effect of Service Transition Strategy on Firm Value, Journal of Marketing 72, 1-14 (2008) https://doi.org/10.1509/jmkg.72.5.1

11. M.M. Hasan, Journal of Contemporary Accounting \& Economics 13, 20-36 (2017) DOI: $10.1016 /$ j.jcae.2017.01.002

12. K.M. Bakarich, M. Hossain, J. Weintrop, Journal of Contemporary Accounting and Economics 15(1), 69-86 (2019) https://doi.org/10.1016/j.jcae.2018.12.002

13. O. Pirogova, V. Plotnikov, Z. Popovic, et al., TransSiberia 2019, AISC 1116, 738-747 (2020) https://doi.org/10.1007/978-3-030-37919-3_73M.

14. A.A. Salisu, I.D. Raheem, U.B. Ndako, Resources Policy 66, 101605 (2020) https://doi.org/10.1016/j.resourpol.2020.101605

15. Ya. Li, D. Zhu, J. Zhao, X. Zheng, L. Zhang, Land Use Policy 94, 104528 (2020) https://doi.org/10.1016/j.landusepol.2020.104528

16. V. Skribans, M. Jurušs, M. Demianchuk, N. Maslii, D. Pastory, Data in Brief. 28, 105064 (2020) https://doi.org/10.1016/j.dib.2019.105064 